\title{
In Finland insulin gene region encoded susceptibility to IDDM exerts maximum effect when there is low HLA-DR associated risk
}

\author{
K.A.Metcalfe ${ }^{1}$, G. A.Hitman ${ }^{1}$, M.J.Fennessy ${ }^{1}$, M. I. McCarthy ${ }^{1}$, J. Tuomilehto ${ }^{2}$, E. Tuomilehto-Wolf ${ }^{2}$, The DiMe \\ (Childhood Diabetes in Finland) Study Group*
}

${ }^{1}$ Department of Medicine, The Royal London Hospital, Whitechapel, London, UK

${ }^{2}$ Department of Epidemiology and Health Promotion, National Public Health Institute, Helsinki, Finland

\begin{abstract}
Summary An association between insulin-dependent diabetes mellitus (IDDM) and polymorphisms of the insulin gene on chromosome 11 p15 (INS) is a consistent finding in Europid populations. While one study suggested that the INS association is restricted to HLA-DR4-positive individuals, studies in other Europid populations have shown the disease-associated INS genotype to confer susceptibility independently of HLA-DR. We have investigated the role of INS in susceptibility to IDDM in Finland, which has the highest incidence of diabetes mellitus in the world, at two polymorphic restriction sites, $5^{\prime}$ and $3^{\prime}$ to the insulin gene. From the DiMe (Childhood Diabetes in Finland) Study we studied 154 diabetic children without regard to HLA-DR type; 108 DR4 positive/non-DR3 diabetic children; 39 DR3 positive/ non-DR4 diabetic children; 30 DR4/DR3 positive diabetic children; 31 non-DR4/non-DR3 diabetic
\end{abstract}

children; 96 matched DiMe control subjects and 86 other healthy, non-diabetic Finnish control subjects. We found an overall association between IDDM and INS in the high-risk Finnish population only with the $5^{\prime}$ polymorphism and identified an INS haplotype negatively associated with IDDM in Finland. However, among diabetic subjects with a reduced HLAassociated susceptibility (non-DR4/non-DR3) both $3^{\prime}$ and $5^{\prime}$ INS loci showed an association with IDDM ( $p$ values 0.02 and 0.0002 , respectively). Thus, in the Finnish population insulin gene-encoded susceptibility to IDDM exerts a maximum effect in those with reduced HLA-associated risk. [Diabetologia (1995) 38: $1223-1229]$

Key words Insulin gene, HLA, haplotype, genetic susceptibility, insulin-dependent diabetes mellitus.
Insulin-dependent diabetes mellitus (IDDM) is a disease of multifactorial origin. It seems likely that the disease occurs due to autoimmune destruction of insulin-producing beta cells of the pancreas in genetically susceptible individuals, after exposure to some

Received: 25 October 1994 and in final revised form: 14 April 1995

Corresponding author: Dr. K.A.Metcalfe, Medical Unit, 5th Floor, Alexandra Wing, The Royal London Hospital, Whitechapel, London E1 1BB UK

Abbreviations: INS, Insulin gene region; VNTR, variable number tandem repeats; PCR, polymerase chain reaction; $\mathrm{RR}$, relative risk; $\mathrm{CI}$, confidence intervals; IDDM, insulin-dependent diabetes mellitus.

* For DiMe Study Group, please see acknowledgements as-yet-unidentified environmental agent. The genetic component of disease susceptibility is complex but genes within the major histocompatibility complex in the HLA Class II region on chromosome $6 p$ account for most of the genetic susceptibility of IDDM [1-3], and the disease is associated with certain alleles of HLA. First described for HLA B8 and B15 $[4,5]$ the association with IDDM was subsequently found to be stronger with HLA DR4 and DR3 in the Class II region [6, 7] which are in linkage disequilibrium with $\mathrm{B} 8$ and $\mathrm{B} 15$, respectively. Later studies demonstrated that in fact the linked alleles at HLA-DQB1 [8, 9] and HLA-DQA1 [10] provide the strongest susceptibility to, or in some cases protection from, disease. A strong association of HLA DR4/DR3 heterozygosity has also been found with IDDM in Caucasians [7], suggesting that the trans 
heterodimer formed from DQB1 and DQA1 encoded molecules strongly predisposes to IDDM.

Finland has the highest incidence of IDDM in the world ( 35 per 100,000 per year), as identified in the DiMe Study [11]. HLA provides the major genetic risk for IDDM in the Finnish population but the HLA association with IDDM in this ethnic group demonstrates a number of unique features. Although both HLA-DR4 and DR3 are associated with the disease, the frequency of DR4/DR3 heterozygosity is not as high as in other diabetic populations [12]. The major genetic risk for IDDM in Finland is determined by a combination of genes on the same HLA haplotype. The DiMe Study also identified a new haplotype - A2,Cw1,B56,DR4,DQ8 which has the highest absolute risk for IDDM (217 per 100,000 per year) when compared to all other haplotypes [13] and is unique to the Finnish population. We have previously shown that a gene(s) in the HLA Class I region also contributes to susceptibility to IDDM in the Finnish population, an effect independent of any linkage disequilibrium with HLA Class II [14].

HLA alone does not account for the complete genetic predisposition to IDDM. Recent genome linkage studies, while confirming that HLA is the major genetic locus, have implicated at least five other non-MHC, minor susceptibility loci for IDDM [3, 15-18]. One of these is the insulin gene region on chromosome 11p15 (INS). The original description of the INS association with IDDM was with the class 1 allele of the VNTR (variable number tandem repeat) identified by Southern blotting [19-21], and in all Europid populations studied the frequency of homozygosity for the class 1 allele of the VNTR is increased in IDDM [22-26]. Subsequent studies have demonstrated tight, though not absolute, linkage disequilibrium of a number of polymorphisms across the INS region [22-26]. Although one study suggested that the INS susceptibility locus resides $3^{\prime}$ to the insulin gene [23] others locate the locus $5^{\prime}$ to the gene [26-28]. One study suggested that the effect of INS was restricted to HLA-DR4-positive individuals [23] but others have found no evidence for an interaction between DR4 and INS indicating that INS confers suceptibility independent of HLA-DR type [20, 24, 26, 29-31]. In our own study of British Caucasoid IDDM subjects we have found a significant association of INS, studied at the VNTR, the $3^{\prime} 1,127$ Pst 1 and the $5^{\prime}-23 \mathrm{Hph} 1$ restriction sites, with IDDM [32]. In contrast to Europid populations in the low-risk Tanzanian, Japanese and South Indian populations no association of INS with IDDM is seen [31,33-34].

To date, however, there have been no studies on the role of non-MHC genes in the susceptibility to IDDM in the Finnish population.

We have investigated the role of insulin gene region encoded susceptibility to IDDM in this ethnic group, and compared the effect of INS in diabetic subjects with different HLA-DR associated risk of disease.

The specific objectives of our study were:

(i) to determine if an association exists in the highrisk Finnish population between IDDM and INS, studied at polymorphisms $5^{\prime}$ and $3^{\prime}$ to the insulin gene, as it does in other Europid populations studied (ii) to investigate if there is any interaction of INS and HLA-encoded susceptibility to IDDM in Finland

\section{Subjects and methods}

\section{Subjects}

(i) Diabetic subjects. The DiMe (Childhood Diabetes in Finland) Study identified all the children in Finland who developed IDDM aged 0-14 years between 1986 and 1989, and they and their families were HLA typed $[11,13,35,36]$. The criteria for the diagnosis of IDDM in the DiMe Study were recommended by the Diabetes Epidemiology Research International Group [37]. INS status was determined in the following newly-diagnosed Finnish diabetic children who were identified in the DiMe Study: 108 HLA-DR4 positive/non-DR3, 39 HLA DR3 positive/non-DR4, 30 HLA-DR4 positive/DR3 positive and 31 HLA non-DR4/non-DR3 children. These subsamples were selected on the basis of HLA-DR status but did not differ significantly from the entire DiMe sample with regard to other HLA alleles, age of diagnosis, sex or family history of IDDM $[13,36]$. The gene frequencies at DR in the non-DR4/non-DR3 diabetic subjects were (with those in the DiMe control subjects in parentheses): DR1 36\% (25\%); DR2 $5 \%(12 \%)$; DR3 0\% (10\%); DR4 0\% (17\%); DR5 $8 \%(8 \%) ;$ DR6 $4 \%(8 \%) ;$ DR7 $11 \%(8 \%) ;$ DR8 $19 \%$ (9\%); DR9 3\% (2\%); DR11 0\% (2\%); DR13 $7 \%(3 \%)$; DR14 $3 \%(1 \%)$. A total of 154 diabetic children serially selected without prior knowledge of HLA-DR status (every third DiMe proband on a sample register for whom blood was available) were also studied and were fully representative of the entire DiMe sample, including at HLA-DR. The gene frequencies of DR4 and DR3 in this group were 44 and $18.5 \%$, respectively, compared to $48(p=0.19)$ and $19.3 \%(p=0.76)$ in the entire DiMe sample $[13,36]$. The frequency of DR4/ DR3 heterozygosity was $21 \%$ compared to $21.6 \%$ in the entire DiMe sample $(p=0.6)$ and was $5 \%$ in the DiMe control subjects.

(ii) Control subjects. We studied 96 Finnish parents of healthy, non-diabetic, age-and sex-matched control subjects from the DiMe Study $(n=96)$. To verify the frequencies of INS genotypes found in the DiMe control subjects we also studied healthy, non-diabetic Finnish control groups from two other studies: 36 elderly men [38] and 50 hospital staff members from the University of Tampere, Finland [39].

Methods. Subjects from the DiMe Study were HLA genotyped by conventional serological techniques, as previously described [13]. INS was studied at the 1,127 Pst 1 polymorphic restriction site in the $3^{\prime}$ untranslated region of the insulin gene and at the 5'-23 $\mathrm{Hph} 1$ polymorphic restriction site. DNA was extracted from blood by a rapid sucrose lysis-proteinase $\mathbf{K}$ digestion method [40]. PCR amplification was performed in 25$\mu l$ volumes containing $1 \mu \mathrm{l}(\sim 50 \mathrm{ng}) \mathrm{DNA}$ lysate, $1.5 \mathrm{mmol} / \mathrm{l}$ $\mathrm{MgCl}_{2}, 200 \mu \mathrm{mol} / 1$ of each $\mathrm{dNTP}, 50 \mathrm{mmol} / \mathrm{L} \mathrm{KCl}, 10 \mathrm{mmol} / \mathrm{l}$ 
Table 1. Frequencies of the 1,127 Pst 1 and -23 Hph 1 INS genotypes $(n)$ in Finnish diabetic subjects and comparison with Finnish control subjects

\begin{tabular}{|c|c|c|c|c|c|c|c|}
\hline$n$ & $\begin{array}{l}\text { Serially-selected } \\
\text { diabetic subjects }\end{array}$ & $\begin{array}{l}\text { DR4 positive/ } \\
\text { non-DR3 } \\
\text { diabetic } \\
\text { subjects } \\
108\end{array}$ & $\begin{array}{l}\text { DR4 positive/ } \\
\text { DR3 positive } \\
\text { diabetic } \\
\text { subjects } \\
30\end{array}$ & $\begin{array}{l}\text { DR3 positive/ } \\
\text { non-DR4 } \\
\text { diabetic } \\
\text { subjects } \\
39\end{array}$ & $\begin{array}{l}\text { non-DR4/non- } \\
\text { DR3 diabetic } \\
\text { subjects } \\
31\end{array}$ & $\begin{array}{l}\text { DiMe } \\
\text { control } \\
\text { subjects } \\
96\end{array}$ & $\begin{array}{l}\text { Total } \\
\text { control } \\
\text { subjects }\end{array}$ \\
\hline 1,127 Pst 1 & & & & & & & $(\mathrm{n}=182)$ \\
\hline$+/+$ & $0.82(127)$ & $0.81(87)$ & $0.77(23)$ & $0.85(33)$ & $0.97(30)$ & $0.79(76)$ & $0.76(138)$ \\
\hline$-23 H \operatorname{Hph} 1$ & & & & & & & $(n=178)$ \\
\hline$+/+$ & $0.76(117)$ & $0.72(78)$ & $0.77(23)$ & $0.82(32)$ & $0.97(30)$ & $0.66(63)$ & $0.63(112)$ \\
\hline$+1-(-1-)$ & $0.24(37)$ & $0.28(30)$ & $0.23(7)$ & $0.18(7)$ & $0.03(1)$ & $0.34(33)$ & $0.37(66)$ \\
\hline $\begin{array}{l}p \text { value vs DiMe } \\
\text { control subjects }^{\mathrm{a}}\end{array}$ & 0.072 & 0.33 & 0.32 & 0.051 & $\begin{array}{l}0.0002 ; \mathrm{RR}=15.7 \\
95 \% \mathrm{CI}=2.01- \\
120.42\end{array}$ & & \\
\hline subjects $^{\mathrm{a}}$ & $1.15-3.0$ & & & $1.13-6.45$ & $\mathrm{CI}=2.36-132.7$ & & \\
\hline
\end{tabular}

a Fisher's exact test

Tris- $\mathrm{HCl}$ ( $\mathrm{pH} 9.0$ ), $0.1 \%$ Triton-X 100, 10 pmol of each primer and 0.54 of Taq polymerase (Promega, Madison, WI, USA) in a Perkin-Elmer Cetus Thermal Cycler (Perkin Elmer Cetus, Norwalk, Conn., USA). The Pst 1 site was amplified for $35 \mathrm{cy-}$ cles $\left(1 \mathrm{~min}\right.$ at $94^{\circ} \mathrm{C}, 1 \mathrm{~min}$ at $55^{\circ} \mathrm{C}$ and $30 \mathrm{~s}$ at $\left.72^{\circ} \mathrm{C}\right)$ with primers G1882 $5^{\prime}$-CTT TAT TCC ATC TCT CTC GGT G- $3^{\prime}$ and G1883 5'-AGC CCT TGG CCC TGG AGG G-3' [22] and the Hph 1 site for 32 cycles $\left(1^{\prime}\right.$ at $94^{\circ} \mathrm{C}, 1^{\prime}$ at $66^{\circ} \mathrm{C}$ and $1^{\prime}$ at $72^{\circ} \mathrm{C}$ ) with primers INS $045^{\prime}$-TCC AGG ACA GGC TGC ATC AG-3' and INS 05 5'-AGC AAT GGG CGG TTG GCT CA $3^{\prime}$ [23]. A total of $8 \mu \mathrm{l}$ of the PCR product was digested with the appropriate restriction enzyme for $2 \mathrm{~h}$. The digested and undigested products were visualised by ethidium bromide staining following electrophoresis in a $4.2 \%$ agarose gel. By convention the disease-associated allele at both sites is denoted as + .

\section{Statistical analysis}

Fisher's exact test (STATXACT-Turbo, Cytel Software Corporation, Cambridge, Mass., USA) was used to calculate exact two-tailed $p$-values and relative risks (RR) for the comparison of the INS genotypes in the different groups of subjects studied. Exact permutational rather than asymptotic analysis was generally preferred when any values for cell frequencies were low. The $95 \%$ confidence intervals (CI) for relative risk were calculated by Mantel Haenszel inference. The comparison of INS genotypes between Finnish diabetic children and control subjects stratified for HLA-DR4 or DR3 positivity was determined by the Test for Homogeneity of Odds Ratios and the exact two-tailed $p$-value calculated (STATXACTTurbo) by the method of Zelen [41] for the comparison of several $2 \times 2$ contingency tables.

\section{Results}

The frequencies of INS genotypes in the groups studied are listed in Table $1 ;+/+$ by convention denotes the IDDM-associated genotype. In view of the high frequency of the 1,127 Pst $1+/+$ genotype found in the DiMe control subjects compared to those from other populations, two other healthy Finnish control groups were also studied. The frequencies of INS genotypes did not differ and were thus most unlikely to be due to any sampling bias. All primary analyses were done on comparison with the DiMe control subjects alone. Any differences on comparison with total pooled control subjects are also presented, however.

The frequencies of the $+/+1,127$ Pst $1(0.79)$ and $+/+-23 \mathrm{Hph} 1$ (0.66) genotypes were statistically different in the DiMe control subjects $(p=0.038)$. At the 1,127 Pst 1 restriction site the frequency of the +1 + INS genotype did not differ between the 154 serially-selected diabetic probands and the DiMe control subjects $(p=0.46)$.

At the $-23 \mathrm{Hph} 1$ restriction site the difference in frequency of the $+/+$ genotype in the 154 serially-selected diabetic probands and the DiMe control subjects did not reach statistical significance $(p=0.072)$. A significant association $(p=0.011 ; \mathrm{RR}=1.86,95 \%$ $\mathrm{CI}=1.15-3.0$ ) was found with the 154 diabetic probands and the $-23 \mathrm{Hph} 1$ polymorphism on comparison with the pooled control subjects $(n=178)$. In order to investigate whether INS susceptibility differed according to HLA-DR susceptibility INS genotype distribution was compared in the HLA DR4 positive/non-DR3, the DR3 positive/non-DR4, the DR4/ DR3 positive and the non-DR4/non-DR3 diabetic subjects. At the $-23 \mathrm{Hph} 1$ site in diabetic subjects there was heterogeneity for INS risk between the HLA-DR subgroups (Fisher's exact test: $p=0.0162$ ) (Table 2); there was no statistical difference between these groups of diabetic subjects when compared at 
the 1,127 Pst 1 site ( $p=0.1$ ). On comparison of each group of diabetic subjects with the DiMe control subjects it appeared that this heterogeneity could be accounted for by a very strong association of the -23 Hph 1 INS polymorphism with the non-DR4/nonDR3 diabetic subjects ( $p=0.0002 ; \mathrm{RR}=15.71,95 \%$ $C I=2.01-120.42$ ). Analysis of the results at the 1,127 Pst 1 restriction site for a similar association also demonstrated the $+/+$ genotype to be significantly more common in the non-DR4/non-DR3 diabetic subjects $(p=0.018 ; \mathrm{RR}=7.9,95 \% \mathrm{CI}=1.01-61.47)$. Comparison of the DR4 positive/non-DR3 or the DR4/DR3 positive diabetic subjects with control subjects did not reach statistical significance at either polymorphism but the DR3 positive/non-DR4 diabetic subjects did show a weak association when compared with the total pooled control subjects at $-23 \mathrm{Hph} 1(p=0.02$; RR $=2.69,95 \% \mathrm{CI}=1.13-$ 6.45).

We further compared the distribution of INS genotype in both diabetic subjects and the 95 HLA genotyped DiMe control subjects stratified for HLADR3 and HLA-DR4 (Table 3). The frequency of the INS $+/+$ genotype was significantly higher in the non-DR4/non-DR3 diabetic than in the non-DR4/ non-DR3 control subjects at both the 1,127 Pst 1 $(p=0.01 ; \quad \mathrm{RR}=10.95 \% \quad \mathrm{CI}=1.24-80.8)$ and -23 Hph $1(p=0.0003 ; \quad \mathrm{RR}=17.27,95 \% \mathrm{CI}=2.18$ $137.1)$ restriction sites. However, there was no difference between diabetic and control subjects who possessed either HLA-DR4 or DR3; and also among the non-diabetic control subjects the frequency of the $+1+$ genotypes did not vary by the presence or absence of HLA-DR3 or HLA-DR4. Comparison of INS genotypes between the Finnish diabetic children and control subjects stratified for HLA-DR4 or DR3 positivity by the test for homogeneity of odds ratios (Table 3) confirmed that there was a significant difference at INS between the non-DR4/non-DR3 diabetic subjects and control subjects compared with the HLA DR4 and DR3 positive diabetic subjects and control subjects at both polymorphic restriction
Table 2. Heterogeneity of INS-encoded susceptibility to IDDM according to HLA-DR status

\begin{tabular}{lll}
\hline Finnish diabetic subjects $\begin{array}{ll}-23 \operatorname{Hph} 1(n) \\
+/+\end{array}$ & $\begin{array}{l}-23 \mathrm{Hph} 1(n) \\
+/- \text { plus }-/-\end{array}$ \\
\hline
\end{tabular}

DR4 positive/

non-DR3

$(n=108)$

$0.72(78)$

$0.28(30)$

DR3 positive/

non-DR4

$(n=39)$

$0.82(32)$

$0.18(7)$

DR4 positive/

DR3

positive $(n=30)$

$0.77(23)$

$0.23(7)$

non-DR4/non-

DR3

$(n=31) \quad 0.97(30) \quad 0.03(1)$

Fisher's exact test (Fisher's statistic $=10.10$ ): exact $p$ value $=0.016$

sites studied (exact $p$ values $=0.027$ for Pst $1 ; 0.015$ for Hph 1).

Comparison of informative individuals for INS haplotypes at the 1,127 Pst 1 and $-23 \mathrm{Hph} 1$ restriction sites also showed a significant difference between the serially-selected representative diabetic group and DiMe control subjects. Ten of 256 diabetic compared to 14 of $152 \mathrm{DiMe}$ non-diabetic haplotypes were ' + ' at the Pst 1 and '-' at the Hph 1 restriction sites $(p=0.03 ; \mathrm{RR}=0.4,95 \%$ CI $0.17-0.93)$. No subjects in the entire study were identified who were '-' at Pst and '+' at Hph.

\section{Discussion}

The results of this study demonstrate no overall association between the $3^{\prime}$ INS polymorphism at the 1,127 Pst I restriction site and IDDM in the high-risk Finnish population. This same polymorphism has shown an association with IDDM in all other Europid populations studied [23-26, 31, 32]. However, a weak asso-

Table 3. Comparison of INS genotype (at $-23 \mathrm{Hph}$ 1) between Finnish diabetic children and control subjects stratified for HLADR4 or DR3 positivity

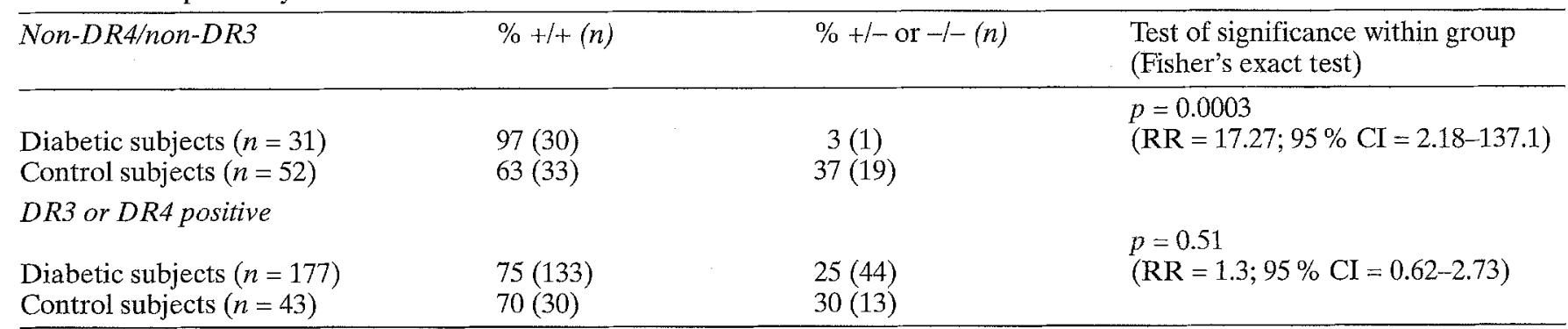

Comparison of the two $2 \times 2$ contingency tables groups by test for homogeneity of odds ratios (by the method of Zelen [41]) exact $p$ value $=0.015$. The exact $p$ value for the same analysis at the 1,127 Pst 1 site is 0.027 HLA serological typing was obtained on 95 of the 96 control subjects typed at INS 
ciation was found with IDDM overall and the $5^{\prime}$ INS polymorphism at the $-23 \mathrm{Hph} 1$ restriction site. Interestingly there was also a significant difference in genotype distribution of the $5^{\prime}$ and $3^{\prime}$ INS polymorphisms studied in healthy, non-diabetic Finnish control subjects, but not in diabetic subjects.

The novel finding of this study is that the INS association was maximal in those diabetic subjects who did not possess HLA-DR associated susceptibility; i. e., who were non-DR4/non-DR3. Direct comparison of the groups of diabetic subjects supported heterogeneity of INS-encoded susceptibility according to HLA-DR status. Our findings do not exclude a weak INS effect in these groups of diabetic subjects which possess high-risk HLA haplotypes, which may be revealed if substantially larger numbers of subjects are studied or if a different methodological approach is taken, such as transmission ratio distortion analysis. Nevertheless, a very strong association was found between both INS polymorphisms and IDDM in the smaller number of diabetic subjects with reduced HLA-associated susceptibility. The further comparison of the distribution of INS genotypes in diabetic and DiMe control subjects matched for HLA-DR risk provides strong supporting evidence for a maximal effect of INS on susceptibility to IDDM in the low HLA-DR risk group.

While HLA undoubtedly confers the major identified genetic risk for IDDM in all populations studied, including the Finns, our results suggest that in those diabetic subjects with reduced HLA-DR encoded susceptibility a gene in the INS region assumes added significance in order to confer susceptibility to disease. Unfortunately, the relative rarity of IDDM subjects who are HLA non-DR4/non-DR3 (4\% in the DiMe Study) means the numbers available for analysis are inevitably small. Therefore it would be of considerable interest to know whether these findings could be reproduced in a separate data set; this type of study may require multi-centre collaboration. Our data is consistent with the hypothesis that in the Finnish population IDDM is determined in some subjects by high-risk HLA haplotypes with only a minor contribution from INS. However, in subjects with lower-risk HLA haplotypes a contribution from INS, and perhaps other non-MHC loci, is required for expression of disease.

The insulin gene is obviously favoured as a candidate gene for IDDM because of its beta-cell specific expression. Several groups have sequenced the insulin gene and the immediate regulatory region in haplotypes associated with IDDM $[42,43]$. No coding region mutations which would lead to a 'mutant' insulin have been identified. Similarly, apart from one eight base pair insertion found in North American blacks [44], no other mutations have been found between the VNTR and the start codon of the insulin gene. The possibility that the VNTR itself, or sequences $5^{\prime}$ to it, have an effect on insulin gene transcription has been the focus of much study and a number have suggested a link between the size of VNTR and insulin secretion [45-47]. Since submission of this manuscript, two studies have reported a direct correlation between allelic variation of the VNTR and insulin gene expression [27, 28]. One of these studies demonstrated that not only is length variation within the VNTR important in insulin gene transcription but also that sequence variation within individual repeats affects binding of a specific insulin gene transcription factor [28]. However, the actual relationship between INS expression and susceptibility to IDDM remains to be explained.

Our results might suggest that the IDDM susceptibility locus is situated on a haplotype in linkage disequilibrium with the ' + ' alleles of the 3 ' and 5 ' polymorphisms. However, we believe the stronger association between the $5^{\prime}$ than the $3^{\prime}$ polymorphism with IDDM, and the finding of the negative association between the '-' Hph 1, '+' Pst 1 INS haplotype and IDDM provides stronger evidence for locating the IDDM susceptibility gene(s) to the $5^{\prime}$ region of INS.

While one study suggested that the IDDM susceptibility gene is likely to be $3^{\prime}$ to the insulin gene itself [23] another provided evidence that it is more likely to be $5^{\prime}$ [26]. This latter study identified an insulin gene with a haplotype which possessed a class 3 VNTR allele, did not restrict at the $-23 \mathrm{Hph} 1$ and 1,127 Pst 1 restriction sites (i.e. '-' at Hph 1; '+' at Pst 1) and was negatively associated with IDDM. The recent study by Bennett et al. [27] also provided strong evidence that INS locus maps to the VNTR itself, and supported the finding of this protective INS haplotype. We also find this haplotype to be negatively associated with IDDM. Furthermore, the significant difference between the $3^{\prime}$ and $5^{\prime}$ INS genotypes in Finnish control subjects, and the absence of an association of IDDM and the 1,127 Pst 1 polymorphism can be explained by the relatively high frequency of this INS haplotype in the healthy Finnish population.

Our results do not support an association or interaction of HLA-DR4 and INS-encoded susceptibility to IDDM in the Finnish population. Indeed it would seem that INS exerts its maximum effect in those Finnish diabetic subjects without the usual HLADR-associated risk. Studies of INS in HLA nonDR4/non-DR3 diabetic subjects in other populations are necessary to determine if INS exerts an extra effect in the absence of high-risk HLA-DR alleles in all IDDM populations, or whether this is another unique feature of the genetics of IDDM in Finland.

Acknowledgements. We thank the British Diabetic Association for generous funding of this work. K.M. is a British Diabetic Association R.D Lawrence Research Fellow. The DiMe study was supported by grants from the National Institute of 
Health, USA (NIH grant DK-7957), the Sigrid Juselius Foundation, the Association Finnish Life Insurance Companies, the Nordisk Insulinfond and the Finnish Foundation for Diabetes Research.

The Childhood Diabetes in Finland (DiMe) Study Group is composed of the following members:

Principal investigators: H. K. Åkerblom, J. Tuomilehto

Co-ordinators: R. Lounamaa, L. Toivanen

Local investigators: A. Fagerlund, M. Flittner, B. Gustafsson, C. Häggqvist, A. Hakulinen, L.Herva, P.Hiltunen, T. Huhtamäki, N.P.Huttunen, T.Huupponen, M.Hyttinen, T.Joki, R.Jokisalo, M.L.Käär, S.Kallio, E.A.Kaprio, U.Kaski, M.Knip, L.Laine, J.Lappalainen, J. Mäenpää, A. L. Mäkelä, K.Niemi, A.Niiranen, A.Nuuja, P.Ojajärvi, T.Otonkoski, K. Pihlajamäki, S. Pöntynen, J. Rajantie, J. Sankala, J. Schumacher, M.Sillanpää, M.R.Ståhlberg, C.H.Stråhlmann, T. Uotila, M. Väre, P. Varimo, G. Wettenstrand

\section{References}

1. Rotter JI, Landaw EM (1984) Measuring the genetic contribution of a single locus to a multilocus disease. Clin Genet 26: $529-542$

2. Risch N (1987) Assessing the role of HLA-linked and unlinked determinants of disease. Am J Hum Genet 40: 1-14

3. Davies JL, Kawaguchi Y, Bennett ST et al. (1994) A genome-wide search for human type 1 diabetes susceptibility genes. Nature 371: 130-136

4. Singal DP, Blajchman MA (1973) Histocompatibility antigens, lymphocytoxic antibodies and tissue antibodies in patients with diabetes mellitus. Diabetes 22: 429-432

5. Nerup J, Platz P, Ortved-Andreson O, Christy M, Lynsgoe J, Poulsen JE (1974) HLA antigens and diabetes mellitus. Lancet 1974: 864-866

6. Sachs JA, Cudworth AG, Jaraquemada D, Gorsuch AN, Festenstein H (1980) Type 1 diabetes and the HLA-D locus. Diabetologia 18: 41-43

7. Wolf E, Spencer KM, Cudworth AG (1984) The genetic susceptibility to type 1 (insulin-dependent) diabetes: analysis of the HLA-DR association. Diabetologia 24: 224 230

8. Festenstein H, Awad J, Hitman GA et al. (1986) New HLA DNA polymorphisms associated with autoimmune diseases. Nature 322: 64-67

9. Todd JA, Bell JI, McDevitt HO (1987) HLA-DQ $\beta$ gene contributes to susceptibility and resistance to insulin-dependent diabetes' mellitus. Nature 329: 599-604

10. Khalil I, dÁuriol L, Gobet M et al. (1990) A combination of HLA-DQ $\beta$ Asp 57-negative and HLA-DQ $\alpha$ Arg52 confers susceptibility to insulin-dependent diabetes mellitus. J Clin Invest 85: 1315-1319

11. Tienari PJ, Tuomilehto-Wolf E, Tuomilehto J, Peltonen L, the DiMe study group (1992) HLA haplotypes in type 1 (insulin-dependent) diabetes mellitus: molecular analysis of the HLA-DQ locus. Diabetologia 35: 254-260

12. Tuomilehto-Wolf E, Tuomilehto J (1990) DR3, DR4 heterozygosity is not the reason for the high incidence of IDDM in Finland. Diabetes 39 [Suppl 21A] : 81 (Abstract)

13. Tuomilehto-Wolf E, Tuomilehto J, Cepaitis Z, Lounamass R, the DiMe Study Group (1989) New susceptibility haplotype for type 1 diabetes. Lancet II: 299-602

14. Fennessy M, Metcalfe KA, Hitman GA et al. (1994) A gene in the HLA class 1 region contributes to susceptibility to IDDM in the Finnish population. Diabetologia 37: 937-944
15. Hashimoto L, Habita C, Beressi JP et al. (1994) Genetic mapping of a susceptibility locus for insulin-dependent diabetes mellitus on chromosome 11q. Nature 371: 161-164

16. Field LL, Tobias R, Magnus T (1994) A locus on chromosome $15 q 26$ (IDDM 3) produces susceptibility to insulindependent diabetes mellitus. Nature Genetics 8: 189-184

17. Copeman JB, Cucca F, Hearne CM et al. (1995) Linkage disequilibrium mapping of a type 1 diabetes susceptibility gene (IDDM 7) to chromosome 2q31-q33. Nature Genetics $9: 80-85$

18. Owerbach D, Gabbay KH (1995) The HOXD8 locus is linked to type 1 diabetes. Interaction with chromosome 6 and 11 disease susceptibility genes. Diabetes 44: 132-136

19. Bell GI, Horita S, Karam JH (1984) A polymorphic locus near the human insulin gene is associated with insulin-dependent diabetes mellitus. Diabetes 33: 176-183

20. Hitman GA, Tarn AC, Winter RM (1985) Type 1 (insulindependent) diabetes and a highly variable locus close to the insulin gene on chromosome 11. Diabetologia 28: 218222

21. Owerbach D, Nerup J (1982) Restriction fragment length polymorphism of the insulin gene in diabetes mellitus. Diabetes 31: 275-277

22. Hitman GA, Kambo PK, Viswanathan M, Mohan V (1991) An analysis of amplified insulin gene products in diabetics of Indian origin. J Med Genet 28:97-100

23. Julier C, Hyer RN, Davies J et al. (1991) Insulin-IGF2 region on chromosome $11 \mathrm{p}$ encodes a gene implicated in HLA-DR4-dependent diabetes susceptibility. Nature 354: 155-159

24. Bain SC, Prins JB, Hearne CM et al. (1992) Insulin gene region encoded susceptibility to type 1 diabetes is not restricted to HLA-DR4-positive individuals. Nature Genetics 2: 212-215

25. Lucassen AM, Julier C, Berressi J-P et al. (1993) Susceptibility to insulin dependent diabetes mellitus maps to a $4.1 \mathrm{~kb}$ segment of DNA spanning the insulin gene and associated VNTR. Nature Genetics 4: 305--310

26. Owerbach D, Gabbay KH (1993) Localization of a type 1 diabetes susceptibility locus to the variable tandem repeat region flanking the insulin gene. Diabetes 42: 1708-1714

27. Bennett ST, Lucassen AM, Gough SCL et al. (1995) Susceptibility to human type 1 diabetes at IDDM 2 is determined by tandem repeat variation at the insulin gene minisatellite locus. Nature Genetics 9: 284-292

28. Kennedy CG, German MS, Rutter WJ (1995) The minisatellite in the diabetes susceptibility locus IDDM2 regulates insulin transcription. Nature Genetics 9: 293-298

29. Raffel LJ, Vadheim CE, Klein R et al. (1991) HLA-DR and the $5^{\prime}$ insulin gene polymorphism in insulin-dependent diabetes mellitus. Metabolism 40: 1244-1248

30. Van der Auwera B, Heimberg H, Shrevens AF, Van Wayenberge C, Flament J, Schuit FC (1993) $5^{\prime}$ insulin gene polymorphism confers risk to IDDM independently of HLA Class II susceptibility. Diabetes 42: 851-854

31. Undlien DE, Hamaguchi K, Kimura A et al. (1994) IDDM susceptibility associated with polymorphisms in the insulin gene region. A study of Blacks, Caucasians and Orientals. Diabetologia 37: 745-749

32. Siddiqi A, Metcalfe KA, Lai M et al. (1994) Susceptibility loci in ICA positive subjects, IDDM and other autoimmune disease: implications for disease prediction. Diabetologia 37 [Suppl 1]: A55 (Abstract)

33. Awata T, Shibasaki Y, Hirai H, Okabe T, Kanazawa Y, Takaku F (1985) Restriction fragment length polymorphism of the insulin gene in Japanese diabetic and non-diabetic subjects. Diabetologia 28: 911-913 
34. Kambo PK, Hitman GA, Mohan V et al. (1989) The genetic predisposition to fibrocalculous pancreatic diabetes. Diabetologia 32: $45-51$

35. Tuomilehto-Wolf E, Tuomilehto J, Hitman GA and the DiMe study group (1992) DQA1 and DQB1 heterodimers in insulin-dependent diabetes mellitus. A genetic-epidemiology study in Finland. Ann Med 24: 533-538

36. Tuomilehto J, Lounamaa R, Tuomilehto-Wolf E et al. (1992) Epidemiology of childhood diabetes mellitus in Finland - background of a nationwide study of type 1 (insulindependent) diabetes mellitus. Diabetologia 35: 70-76

37. Diabetes epidemiology research international group (1988) Geographic patterns of childhood insulin-dependent diabetes mellitus. Diabetes 37: 1113-1119

38. Tuomilehto-Wolf E, Tuomilehto J, Hitman GA et al. (1993) Genetic susceptibility to non-insulin-dependent diabetes mellitus and glucose intolerance are located in the HLA region BMJ 307: 155-159

39. Medcraft J, Hitman GA, Sachs JA, Whichelow CE, Raafat I, Moore RH (1993) Autoimmune renal disease and tumour necrosis factor $\beta$ gene polymorphism. Clin Nephrol 40: $63-68$

40. Balnaves ME, Nasioulas S, Dahl H-HM, Forrest S (1991) Direct PCR from CVS and blood lysates for detection of cystic fibrosis and Duchenne muscular dystrophy deletions. Nucleic Acids Res 19: 115
41. Zelen M (1971) The analysis of several $2 \times 2$ contingency tables. Biometrika 58(1): 129-137

42. Bell GI, Pictet RL, Ruffer WJ, Cordell B, Tischer E, Goodman HM (1980) Sequence of the human insulin gene. Nature 384: 26-32

43. Ullrich A, Dull TJ, Gray A, Brosias, Sures I (1980) Genetic variation in the human insulin gene. Science 209: 612-615

44. Olansky L, Welling C, Giddings S et al. (1992) A variant insulin promoter in non-insulin-dependent diabetes. J Clin Invest 89: 1596-1602

45. Cocozza S, Riccardi G, Antonella M (1988) Polymorphism at the $5^{\prime}$ end flanking region of the insulin gene is associated with reduced insulin secretion in healthy individuals' secretion. Eur J Clin Invest 18: 582-586

46. Amos CI, Cohen JC, Srinivasan SR et al. (1989) Polymorphism in the $5^{\prime}$ flanking region of the insulin gene and its potential relation to cardiovascular disease risk: observations in a biracial community. The Bogalusa Heart Study. Atherosclerosis 79: $51-57$

47. Weaver JU, Kopelman PG, Hitman GA (1992) The hyperinsulinaemia of obesity is associated with polymorphisms in the $5^{\prime}$ flanking region of the insulin gene. Eur J Clin Invest $22: 265-270$ 